\title{
Article/Artigo
}

\section{Plasmodium falciparum infection in pregnant women attending antenatal care in Luanda, Angola}

\author{
Infecção por Plasmodium falciparum em mulheres grávidas em consultas pré-natal em Luanda, Angola
}

Paulo Adão Campos ${ }^{1,2}$, Bianor Valente ${ }^{1}$, Rosa Bessa Campos ${ }^{3}$, Luzia Gonçalves ${ }^{4,5}$, Virgílio Estóliodo Rosário ${ }^{1}$, Luís Varandas ${ }^{1,6}$ and Henrique Silveira ${ }^{1}$

\begin{abstract}
Introduction: Malaria during pregnancy remains a serious public health problem. The aim of this study was to establish the prevalence and possible risk factors for malaria in pregnant women attending antenatal care at Augusto Ngangula Specialized General Hospital in Luanda, Angola. Methods: Pregnant women (679 total) who attended antenatal care from April to September 2008 were included in the study after signing informed consent. For each participant, the social-demographic profile and malaria and obstetric histories were investigated via a questionnaire. Diagnosis was made by optic microscopy, and hemoglobin concentration measured. The associations between age, parity, gestational age, residence, schooling, malaria during gravity, anemia and treatment with incidence of Plasmodium falciparum infection were analyzed through logistic regression. Results: During the period of study, 74 (10.9\%) out of 679 women were infected by P. falciparum. The average concentration of hemoglobin was 11.1 $\pm 0.07 \mathrm{~g} / \mathrm{dL}$, and there were significant associations between the history of malaria during pregnancy, P. falciparum infection $(\mathrm{p}<0.01)$ and anemia at the time of observation $(\mathrm{p}<0.001)$. Conclusions: Previous history of malaria during pregnancy represents a risk factor for current infection and anemia was an important complication associated with malaria, even in women who were treated with sulfadoxine-pyrimethamine during pregnancy.
\end{abstract}

Keywords: Malaria. Pregnancy. Africa. Prevalence. Stable transmission.

\section{RESUMO}

Introdução: A malária na gravidez continua a ser um grave problema de saúde pública. $\mathrm{O}$ objetivo deste estudo foi determinar a prevalência e possíveis fatores de risco para a malária, em mulheres grávidas que foram atendidas em consultas pré-natal, no Hospital Geral Especializado Augusto Ngangula, em Luanda, Angola. Métodos: De abril a setembro de 2008, 679 mulheres grávidas foram envolvidas no estudo após consentimento informado. O perfil sócio demográfico e história de malária e obstetrícia foram investigados através de um questionário. O diagnóstico foi efetuado por microscopia óptica e determinou-se ainda as concentrações da hemoglobina. Através da regressão logística foi analisada a associação entre a idade, paridade, tempo de gestação, residência, escolaridade, malária durante a gravidez, anemia e tratamento com a infecção por Plasmodium falciparum. Resultados: Setenta e quatro (10,9\%) das 679 mulheres estavam infectadas com P. falciparum. O valor médio da concentração da hemoglobina foi de $11,1 \pm 0,07 \mathrm{~g} / \mathrm{dL}$, encontrando-se uma associação significativa entre história de malária na gravidez e infecção por P.falciparum $(\mathrm{p}<0,01)$ e anemia no momento da observação $(\mathrm{p}<0.001)$. Conclusões: A história de malária anterior na gravidez foi um fator de risco para uma infecção atual e a anemia uma complicação importante associada à malária, mesmo em mulheres que receberam tratamento durante a gravidez com sulfadoxina-pirimetamina.

Palavras-chaves: Malária. Gravidez. África. Prevalência. Transmissão estável.

1. Centro de Malária e outras Doenças Tropicais, Unidade de Ensino e Investigação Parasitologia Médica, Instituto de Higiene e Medicina Tropical, Universidade Nova de Lisboa, Lisboa, Portugal. 2. Departamento de Ginecologia e Obstetrícia, Faculdade de Medicina, Universidade Agostinho Neto, Luanda, Angola. 3. Hospital Geral Especializado Augusto Ngangula, Luanda, Angola. 4. Unidade de Saúde Pública Internacional e Bioestatística, Instituto de Higiene e Medicina Tropical, Universidade Nova de Lisboa, Lisboa, Portugal. 5. Centro de Estatística e Aplicações, Universidade de Lisboa, Lisboa, Portugal 6. Unidade de Ensino e Investigação Clínica das Doenças Tropicais, Instituto de Higiene e Medicina Tropical, Universidade Nova de Lisboa, Lisboa, Portugal.

Address to: Dr. Paulo Adão de Campos. Departamento de Ginecologia e Obstetrícia/Faculdade de Medicina da Universidade Agostinho Neto. Av. Hojy-Ya-Henda, CódigoPostal 116, Luanda, Angola. Phone: 002449 2341-2961

e-mail: paulocampos44@gmail.com

Received in 28/07/2011

Accepted in 11/11/2011

\section{INTRODUCTION}

Malaria from Plasmodium falciparum during pregnancy is a serious public health problem in Sub-Saharan Africa. More than 50 million women residing in malaria-endemic areas become pregnant every year ${ }^{1-3}$. Although malaria during pregnancy might be asymptomatic due to the development of some degree of immunity by mothers residing in areas with stable transmission, it is still associated with unfavorable effects on the mother or the child ${ }^{4-8}$. For this reason, abortions, stillbirths, premature deliveries and maternal deaths are common phenomena ${ }^{9,10}$. Many, if not most, cases of maternal and perinatal death can be prevented ${ }^{11}$.

The impact of malaria-related anemia on pregnant women (id est., the risk of death) and fetuses (i.e., low birthweight) has been increasingly acknowledged during the last decades ${ }^{12,13}$, keeping in mind that anemia does not necessarily have to be symptomatic to become a risk factor during pregnancy. Low birth weight in newborns from mothers who had malaria during pregnancy is common; it is estimated that it causes $5 \%$ of perinatal deaths in areas with poor resources ${ }^{14}$. The prevalence of infection and the density of parasites reach their peak during the first half of pregnancy and progressively decrease until delivery ${ }^{15}$.

Factors that influence the prevalence of malaria in pregnant women were identified and include maternal age, parity, use of prophylaxis, nutrition, genetics of the host, level of anti-parasitic immunity and genetics of the parasite ${ }^{16}$.

During the last decade, several studies were performed in African countries with high indices of transmission ${ }^{17-24}$; however, few data were published for Angola, which is one of the five countries with the lowest available amounts of information regarding malaria during pregnancy, a fact that makes decisionmaking for prevention and control difficult ${ }^{25}$. The aim of this study was to assess the prevalence of $P$. falciparum and its possible associated risk factors in pregnant women who attended antenatal care in Luanda. 


\section{METHODS}

\section{Setting of the study and participants}

A transversal study was performed at the antenatal care (ANC) facility at Augusto Ngangula Specialized General Hospital (Hospital Geral Especializado Augusto Ngangula - HGEAN) in Luanda, Angola. The study was performed during the high-transmission season, from April to September 2008. Pregnant women were recruited during routine antenatal visits. All patients were invited to participate in the study. Only those who gave informed consent were included; women with other diseases, particularly HIV carriers, were excluded. Each participant was evaluated only once.

\section{Data collection}

Data on malaria in pregnant women who attended ANC at HGEAN were obtained via a questionnaire including the following information: social-demographic profile, malaria history and obstetric history, including age, parity, gestational age and place of residence. Gestational age was calculated from the last menstruation date and via ultrasound when there was uncertainty. The obstetric physical exam helped to complete the required data (blood pressure, paleness of conjunctiva, level of the uterine fundus and fetal heart rate).

\section{Blood collection and microscopic diagnosis}

Blood was collected through digital or venous puncture. Samples were prepared for parasite detection and estimation of parasitemia. Blood smear and thick drop assays were prepared according to the protocol described by the World Health Organization (WHO ${ }^{26}$. Blood smear and thick drop assays were stained with $10 \%$ Giemsa dye. Smears were fixed with methanol for one minute before staining. Parasite density was assessed by counting parasites in 200 leukocytes, assuming that each woman had 8,000 leukocytes/ $\mu \mathrm{L}$ of blood. Smears were rated negative when there were no parasites in 200 fields of a thick drop smear in immersion oil ${ }^{27}$.

\section{Hemoglobin determination}

Hemoglobin concentrations were determined by the hematic acid method using a hemoglobinometer (HaemoCue, Switzerland) in all 679 cases in the study.

\section{Statistical analysis of data}

Data were stored in a Windows Microsoft Excel ${ }^{\oplus}$ spreadsheet and were revised for verification. The software SPSS v.18.0 for Windows (SPSS, Inc.) was used to analyze data.

An exploratory and descriptive analysis of variables (some of which were re-codified) was performed. For continuous variables, comparisons between two or more independent groups were analyzed using Mann-Whitney U and Kruskal-Wallis tests, after the failures of the presuppositions of the parametric tests (Student's t-test and ANOVA) were verified. For qualitative variables, the Pearson Chi-Square test was used. A value of $\mathrm{p}<0.05$ was considered significant. For estimation of the prevalence of $P$.falciparum infection with a $95 \%$ confidence interval (CI), the Agresti-Coull, Wilson or Jeffreys methods were used, as recommended ${ }^{28}$. As described below, simple and multiple logistic regression models were also used ${ }^{29,30}$. To identify a simpler model, a Backward/Wald procedure was also used to automatically discard non-significant variables.
The variable malaria (including with and without P. falciparum infection categories) was considered the dependent variable; age, parity, gestational age, residence, schooling, (previous) malaria during pregnancy and treatment were considered independent variables. Variables were categorized as follows: age ( $\leq 18$ yearsold, 19-24 yearsold, $>24$ yearsold); parity [primiparous and multiparous ( $\geq 2$ births)]; gestational age [first trimester ( $<14$ weeks), second trimester (14-27 weeks) and third trimester ( $\geq 28$ weeks)]; and treatment during pregnancy [no treatment, sulfadoxinepyrimethamine treatment and other drugs]. Hemoglobin concentrations were classified as anemia $(<11 \mathrm{~g} / \mathrm{dL})$, severe anemia $(<7 \mathrm{~g} / \mathrm{dL})$ and normal $(\geq 1 \mathrm{~g} / \mathrm{dL})$.

Simple and multiple logistic regressions were used to analyze potential risk factors associated with the presence of ongoing $P$. falciparum infection. To investigate the association between the several independent variables and malaria, we began by performing simple logistic regressions with each independent variable.

Next, we applied multiple regression models to control possible confusion. Variables exhibiting statistically significant associations $(\mathrm{p}<0.05)$ or with important epidemiological meanings were included. These co-variables were kept in models, independent of their significance, in univariate analysis due to their possible relevance in the final results; thus, we could analyze their possible influence when considered together with the other variables. The first model included the independent variables treatment, age, anemia (with and without infection), parity and malaria during pregnancy; the second model also included gestational age.

\section{Ethical considerations}

This study was approved by the Ethics Committee of the Faculty of Medicine of Agostinho Neto University, Luanda, Angola.

\section{RESULTS}

\section{Population study}

Data were collected from a total of 679 pregnant women who attended ANC at HGEAN. The demographic and obstetric profiles and the parasitological-hematological data were collected from the participants. These profiles are summarized in Table 1. Briefly, the ages of the women ranged between 12 and 42 years (mean $=25.7$ years and median $=25$ years); most women $(66.1 \%)$ had a low schooling level, most were multiparous (74.1\%), and more were in the second trimester of pregnancy $(46.2 \%)$ than were in either the first or third trimesters.

Optical microscopy performed at the time of the study showed mono-infection by P. falciparum in $10.9 \%(\mathrm{n}=74)$ of women $(\mathrm{n}=679)$, with a $95 \%$ CI between $8.8 \%$ and $13.5 \%$. Distribution according to gestational age was as follows: $1^{\text {st }}$ trimester $=9.7 \%(n=18)$, $2^{\text {nd }}$ trimester $=11.5 \%(n=36 \%)$, and $3^{\text {rd }}$ trimester $=11.1 \%(n=20)$. Details on parasitemia and the stratification of parity and gestational age are summarized in Table 2. The prevalences of $P$. falciparum (expressed in percentages) in primiparous (11.9\%) and multiparous (10.5\%) women were not significantly different. Additionally, the densities of parasites between primiparous and multiparous women were not significantly different. The rates of infection according to pregnancy trimester (expressed in percentages) were higher in the second and third trimesters (though these rates were not statistically significant). 
TABLE 1 -Demographic and obstetric profiles of the participants $(n=679)$ in the study.

\begin{tabular}{lcc}
\hline Demographic and obstetric profiles & Number & Pecentage \\
\hline Age (years) & \multicolumn{2}{c}{25} \\
$\quad$ median & \multicolumn{2}{c}{$12-42$} \\
minimum-maximum & 449 & 66.1 \\
\hline Education & 230 & 33.9 \\
$\quad$ no or basic schooling & & \\
secondary or higher & 160 & 23.6 \\
\hline Residence & 319 & 76.4 \\
$\quad$ urban & & \\
peri-urban & 176 & 25.9 \\
\hline Parity & 503 & 74.1 \\
primiparous $^{\text {multiparous }}$ & & \\
\hline Gestational age & 185 & 27.3 \\
$1^{\text {st }}$ trimester $(<14$ weeks $)$ & 314 & 46.2 \\
$2^{\text {nd }}$ trimester $(14-27$ weeks $)$ & 180 & 26.5 \\
$3^{\text {rd } \text { trimester }(\geq 28 \text { weeks })}$ & & \\
\hline
\end{tabular}

The mean and standard deviation of hemoglobin concentration in the studied samples was $11.1 \pm 0.07 \mathrm{~g} / \mathrm{dL}$, and the median was $10 \mathrm{~g} /$ dL.When comparing the median values of hemoglobin concentration between $P$. falciparum-infected $(9.9 \mathrm{~g} / \mathrm{dL})$ and non-infected $(11.1 \mathrm{~g} / \mathrm{dL})$ pregnant women, a highly significant difference was identified $(p<0.001)$. It is notable that the values of serum hemoglobin in noninfected women had a tendency for greater dispersion (Figure 1).

A significant association $(\mathrm{p}<0.001)$ was found between anemia (defined as a hemoglobin concentration $<11 \mathrm{~g} / \mathrm{dL}$ ) and the presence/ absence of P. falciparum; among the 339 anemic women, 56 (16.5\%) were infected with P.falciparum, whereas among the 337 non-anemic women, only 17 (5\%) were infected (Table 3). Only eight (1.2\%) women fell into the category of severe anemia $(<7 \mathrm{~g} / \mathrm{dL})$, and none had malaria. For this reason, logistic regression recorded some numerical instabilities; in later analysis, we only considered categories with or without anemia, independent of its severity. We also observed that anemia was associated with gestational age and treatment.

When women were classified as primiparous or multiparous, both primiparous and multiparous women infected with P. falciparum showed a (non-significant) tendency for lower values

TABLE 2 - Rate of Plasmodium falciparum prevalence in women who attended the Augusto Ngangula SpecializedGeneral Hospital (HGEAN), according to the demographic and obstetric variable categories.

\begin{tabular}{|c|c|c|c|c|}
\hline \multirow[b]{2}{*}{ Demographic and obstetric variables } & \multicolumn{3}{|c|}{ Pregnant women } & \multirow[b]{2}{*}{$\mathbf{P}^{*}$} \\
\hline & $\begin{array}{c}\text { with } \\
\text { infection }\end{array}$ & $\begin{array}{l}\text { without } \\
\text { infection }\end{array}$ & $\begin{array}{c}\% \text { of } \\
\text { infected }\end{array}$ & \\
\hline Age (years) & & & & 0.552 \\
\hline$<18$ & 5 & 43 & 10.4 & \\
\hline $19-24$ & 25 & 242 & 9.4 & \\
\hline Parity & & & & 0.350 \\
\hline primiparous & 31 & 155 & 11.9 & \\
\hline multiparous & 53 & 450 & 10.5 & \\
\hline \multicolumn{5}{|l|}{ Education } \\
\hline no or basic schooling & 46 & 403 & 10.2 & 0.270 \\
\hline secondary and higher & 28 & 202 & 13.8 & \\
\hline urban & 15 & 145 & 9.4 & 0.292 \\
\hline peri-urban & 59 & 460 & 11.4 & \\
\hline \multicolumn{5}{|l|}{ Gestational age } \\
\hline $1^{\text {st }}$ trimester $(<14$ weeks $)$ & 18 & 167 & 9.7 & 0.830 \\
\hline $2^{\text {nd }}$ trimester (14-27 weeks) & 36 & 278 & 11.5 & \\
\hline $3^{\mathrm{rd}}$ trimester $(\geq 28$ weeks $)$ & 20 & 160 & 11.1 & \\
\hline \multicolumn{5}{|l|}{ Treatment } \\
\hline without & 50 & 420 & 10.6 & 0.464 \\
\hline sulfadoxine-pyrimethamine & 12 & 109 & 9.9 & \\
\hline other & 11 & 62 & 15.1 & \\
\hline don't know/no answer & 1 & 14 & 6.7 & \\
\hline Total & 74 & 605 & 10.9 & \\
\hline
\end{tabular}

*Value of $\mathrm{p}$ according to the Pearson Chi-Square test. 


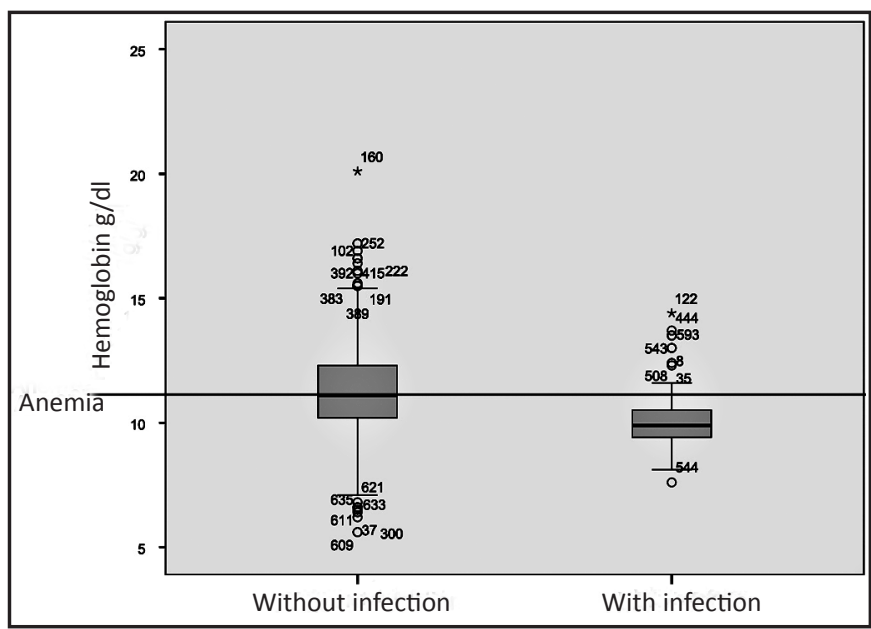

FIGURE 1 - Concentrations of serum hemoglobin in pregnant women with and without malaria. Star: possible extreme outliers; open circle: possible outliers.

TABLE 3 -Anemia among women as a function of gestational age and treatment.

\begin{tabular}{|c|c|c|c|c|c|}
\hline \multirow[b]{3}{*}{ Caracteristics } & \multicolumn{4}{|c|}{ Women } & \multirow[b]{3}{*}{$\mathrm{P}^{*}$} \\
\hline & \multicolumn{2}{|c|}{ without anemia } & \multicolumn{2}{|c|}{ with anemia } & \\
\hline & $\mathbf{n}$ & $\%$ & $\mathbf{n}$ & $\%$ & \\
\hline Gestational age & & & 0.001 & & \\
\hline $1^{\text {st }}$ trimester & 114 & 33.8 & 70 & 20.6 & \\
\hline $2^{\text {nd }}$ trimester & 141 & 41.8 & 172 & 50.7 & \\
\hline $3^{\text {rd }}$ trimester & 82 & 24.3 & 97 & 28.6 & \\
\hline \multicolumn{6}{|l|}{ Treatment } \\
\hline without & 260 & 78.1 & 217 & 64.4 & $<0.001$ \\
\hline sulfadoxine-pyrimethamine & 41 & 12.3 & 80 & 23.7 & \\
\hline other & 32 & 9.6 & 40 & 11.9 & \\
\hline
\end{tabular}

*Value of $\mathrm{p}$ according to the Pearson Chi-Square test.

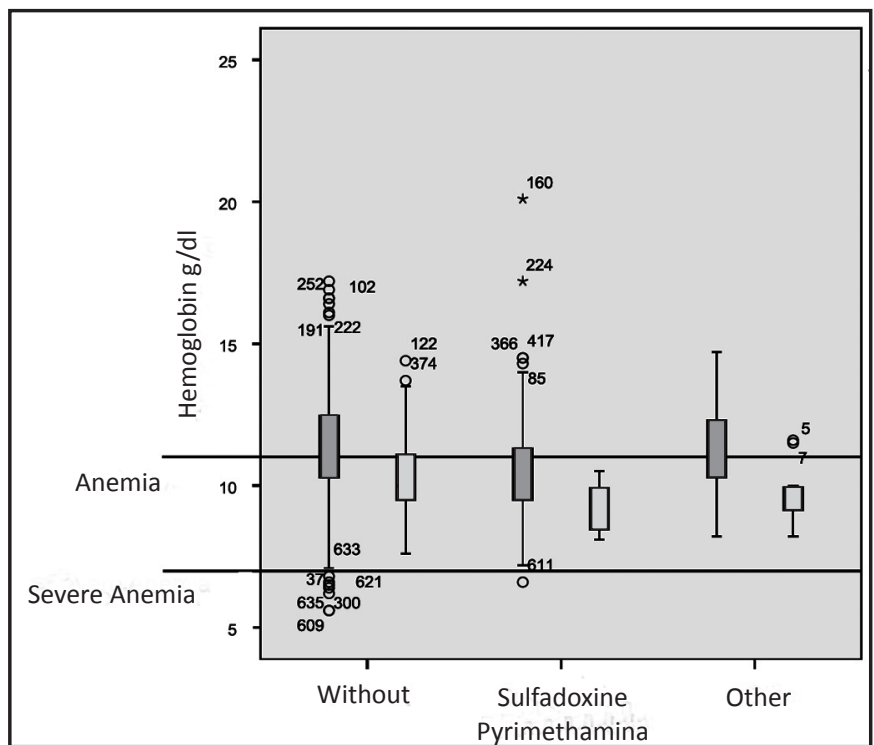

FIGURE 2 - Concentrations of serum hemoglobin in pregnant women as a function of treatment and presence of malaria. Star: possible extreme outliers; open circle: possible outliers. of circulating hemoglobin than did women who were not infected with P. falciparum.

When comparing the median values of hemoglobin levels and types of treatment, significant differences were identified $(p<0.001$, Kruskal-Wallis test). Multiple comparisons showed that hemoglobin levels in women treated with sulfadoxine-pyrimethamine differed significantly from both untreated women and women treated by other means. When classified according to their current state of infection, this pattern of differences between treatments was maintained in non-infected women $(\mathrm{p}<0.001)$ (Figure 2; blue). In infected women, there were still significant differences $(p=0.023)$ between treatments (Figure 2; green); there were differences in hemoglobin concentrations only between sulfadoxine-pyrimethamine-treated and untreated women.

When a multiple logistic regression model was applied that included the variables treatment, age, anemia, parity, malaria during pregnancy and gestational age, only anemia and malaria during pregnancy showed significant associations with current malaria.

Infection was significantly more common in women with anemia than in those without [Relative risk estimated by odds ratio $(\mathrm{OR})=4.03$, 95\% CI 2.23-7.27].Women who had previous malaria during pregnancy also had a higher risk of current malaria [OR $=4.86,95 \%$ CI 1.45-16.25].

Finally, when a Backward/Wald-like procedure was used, we ended in stage 5 , including only anemia and malaria during pregnancy in the models, thus strengthening the association of these variables with current malaria.

\section{DIsCussion}

Malaria is an avoidable cause of maternal and fetal mortality and morbidity; however, the international community is far from implementing the necessary interventions to drastically reduce the impact of this disease in the countries where it is endemic. Early detection and timely and adequate treatment are essential requirements for reducing the incidence of deaths and must be the main components of anti-malaria intervention in underdeveloped countries $^{6-8}$. This study sought to characterize the pattern of malariarelated morbidity during pregnancy at Augusto Ngangula Specialized General Hospital in Luanda, Angola, an urban area rated as having stable transmission by the Department of Endemics Control. The prevalence of malaria during pregnancy was $10.9 \%$ (95\% CI $8.8 \%$ $13.5 \%)$, which agrees with the prevalence in African countries that are characterized as having intense transmission of malaria ${ }^{8,17,21}$. This study showed that there was no association between malaria and parity, as has also been reported by other studies performed in areas with intense transmission of malaria ${ }^{31}$. In areas where transmission is high, the level of acquired immunity is significant, and primiparous women are the most affected ${ }^{17,21}$; however, our study found a larger affected number among multiparous women. In this study, the ages of infected and non-infected women were not significantly different.

This agrees with some data published in the literature ${ }^{18}$; however, other studies performed in Sub-Saharan Africa have reported a significant association between maternal age and malaria during pregnancy ${ }^{17,32}$. Women who attended antenatal care during the second and third trimesters of pregnancy exhibited higher prevalences of malaria infection. This agrees with several studies that have reported the second trimester, along with the beginning of the 
third trimester, as the peak of prevalence ${ }^{15,19,21,33,34}$. However, other studies have named the first trimester as the major risk period ${ }^{21}$. Our limitation resides in the fact that in high transmission areas, many P. falciparum infections during pregnancy stay undetected when only microscopy of Giemsa-stained blood smears of peripheral blood is used for diagnosis. These sub-microscopic infections can only be diagnosed by detection of circulating parasitic antigens or detection of parasite-specific DNA using conventional polymerase chain reaction (PCR), nested PCR, or the more recently developed real-time $\mathrm{PCR}^{5,35-37}$.

Currently intermittent presumptive treatment in pregnancy is recommended by the $\mathrm{WHO}$ for areas of high malaria transmission. Sulfadoxine-pyrimethamine has been reported as the drug of choice, for its effectiveness to eliminate completely P. falciparum infections and therefore prevent adverse birth outcome caused by submicroscopic parasitemia, including anemia and low birth weight ${ }^{38}$.

The average concentration of hemoglobin was significantly lower in infected women as described previously for malaria ${ }^{12,13}$.

Additionally, in this study, women who reported having used sulfadoxine-pyrimethamine had lower concentrations of hemoglobin than women who used other treatments, a fact that might suggest that soon, these drugs will no longer be efficacious. However, the results of a recent study performed in Luanda showed the presence (still relatively low) of markers of resistance (9\%) to sulfadoxinepyrimethamine compared to chloroquine resistance markers ${ }^{39}$. In spite of this, in some areas of Angola (Huambo and Bié), resistance to sulfadoxine-pyrimethamine has reached $25 \%{ }^{40}$. Thus, the efficacy of treatment with these drugs must be evaluated and monitored, as should the preventive intermittent treatment (PIT) that a recent study performed in Ghana showed was still efficient for reducing the levels of anemia associated with malaria ${ }^{41}$.

Our results suggest that $P$. falciparum is common in pregnant women attending antenatal care in Luanda and that anemia is an important complication associated with $P$. falciparum infection. The second trimester of pregnancy seems to represent the peak of highest risk, a fact that might support decision-making concerning PIT with sulfadoxine-pyrimethamine and the use of anti-mosquito nets, as is currently recommended in Angola.

\section{ACKNOWLEDGMENTS}

We extend our grateful thanks to the Angolan women, especially the pregnant women attending antenatal care at Augusto Ngangula Specialized General Hospital, who made this study possible. We also thank Eng. Rodrigues José Capitão for his interest in this study.

\section{CONFLICT OF INTEREST}

The authors declare that there is no conflict of interest.

\section{FINANCIAL SUPPORT}

This study was supported by the Faculty of Medicine of AgostinhoNeto University(UAN) and the Health Ministry of Angola. This study was partly funded by the PROCAPS, program for health resource training in Angola, developed by CMDT/IHMT, in partnership with the Health Ministry of Angola and the Portuguese Institute to Support Development (IPAD).

\section{REFERENCES}

1. World Health Organization (WHO). A strategic framework for malaria prevention and control during pregnancy in the Africa region. Brazzaville: WHO Regional Office for Africa; 2004.

2. Menendez C, Ordi J, Ismail MR. The impact of placental malaria on gestational age and birth weight. J Infect Dis 2000; 181:1740-1745.

3. Terkuile FO, Terlouw DJ, Phillips-Howard PA. Reduction of malaria during pregnancy by permethrin-treated bed nets in an area of intense perennial malaria transmission in western Kenya. Am J Trop Med Hyg 2003; 68:50-60.

4. Kayentao K, Kodio M, Newman RD, Maiga H, Doumtabe D, Ongoiba A. Comparison of intermittent preventive treatment with chemoprophylaxis for the prevention of malaria during pregnancy in Mali.J Infect Dis 2005;191:109-116.

5. Adegnika AA, Verweij JJ, Agnandji ST, Chai SK, Breitling LP, Ramharter M Microscopic and sub-microscopic Plasmodium falciparum infection, but not inflammation caused by infection, is associated with low birth weight. Am J Trop Med Hyg 2006; 75:798-803.

6. Uddenfeldt Wort U, Hastings I, Bergstrom S, Massawe S, Lipingu C, Brabin BJ Increased postpartum blood loss in pregnancies associated with placental malaria. Int J Gynaecol Obstet 2007; 96:171-175.

7. Vallely A, Vallely L, Changalucha J, Greenwood B, Chandranohan D. Intermittent preventive treatment for malaria in pregnancy in Africa: what's new, what's needed? Malar J 2007; 6:16.

8. Enato EFO, Mens PF, Okhamafe AO, Okpere EE, Pogoson E, Schallig HDFE Plasmodium falciparum malaria in pregnancy: prevalence of peripheral parasitaemia, anaemia and malaria care-seeking behaviour among pregnant women attending two antenatal clinics in Edo State, Nigeria. J Obstet Gynaecol 2009; 29:301-306.

9. Feresu SA, Harlow SD, Woelk GB. Risk factors for prematurity at Harare Maternity Hospital, Zimbabwe. Int J Epidemiol 2004; 33:1194-1201.

10. Marchant T, Schellenberg JA, Nathan R. Anaemia in pregnancy and infant mortality in Tanzania. Trop Med Int Health 2004; 9:262-266.

11. Hinderaker SG, Olsen BE, Bergajo PB. Avoidable stillbirths and neonatal deaths in rural Tanzania. BJOG 2003; 110:616-623.

12. Shulman CE, Dorman EK, Blumer JN. Malaria as a cause of severe anaemia in pregnancy. Lancet 2002;360:494.

13. Menendez C, Fleming AF, Alonso PL. Malaria-related anaemia. Parasitol Today 2000; 16: 469-476.

14. Guyatt HL, Snow RW. Impact of malaria during pregnancy on low birth weight in sub-Saharan Africa.Clin Microbiol Rev 2004;17:760-769.

15. Brabin BJ. An analysis of malaria infection in Africa. Bull World Health Organ 1983; 61:1005-1016.

16. Tako EA, Zhou A, Lohoue J, Leke R, Taylor DW, Leke RF. Risk factors for placental malaria and its effect on pregnancy outcome in Yaoundé, Cameroon. Am J Trop Med Hyg 2005; 72:236-242.

17. Rogerson SJ, Van den Broek NR, Chaluluka E, Qongwane C, Mhango CG, Molyneux ME. Malaria and anaemia in antenatal women in Blantyre, Malawi: a twelve-month survey. Am J Trop Med Hyg 2000; 62:335-340.

18. Ladner J, Leroy V, Simonon A, Karita E, Bogaerats J, Clercq AD, et al HIV infection, malaria, and pregnancy: aprospective cohort study in Kigali, Rwanda. Am J Trop Med Hyg 2002; 66:56-60.

19. Dafallah SE, El-Agib FH, Bushra GO. Maternal mortality in a teaching hospital in Sudan. Saudi Med J 2003; 24:369-373.

20. Newman RD, Hailmariam A, Jimma D, Degefie A, Kebede D, Rietveld AC, et al Burden of malaria during pregnancy in areas of stable and unstable transmission in Ethiopia during a non epidemic year. J Infect Dis 2003;187:1765-1772.

21. Dicko A, Mantel C, Thera MA, Doumbia S, Diallo M, Diakete M, et al. Risk factors for malaria infection and anemia for pregnant women in the Sahel area of Bandiagara, Mali. Acta Trop 2003;89:17-23.

22. Adam I, Elbashir MI. Comments on "Risk factors for malaria infection and anemia for pregnant women in the Sahel area of Bandiagara, Mali” by A. Dicko et al. Acta Trop 2005; 96:60-61.

23. Brabin BJ, Johnson PM. Placental malaria and pre-eclampsia through the looking glass backwards? J Reprod Immunol 2005; 65:1-15. 
24. Demba S, Marrama L, Gaye A, Dangou JM, Niang M, Mercereau-Puijalon O, et al. High prevalence of placental malaria and low birth weight in sahelian periurban area. Am J Trop Med Hyg 2006; 75:171-177.

25. Guerra CA, Gikandi PW, Tatem AJ. The limits and intensity of Plasmodium falciparum transmission: implications for malaria control and elimination worldwide. PLoS Med 2008; 5:e38.

26. World Health Organization (WHO). Basic laboratory methods in medical parasitology. Geneva: WHO Library Cataloguing in Publication Data; 1991.

27. Shute GT. The microscopic diagnosis of malaria. In:Wernersdorfer $\mathrm{WH}$, McGreogor I, editors. Malaria: principles and practice of malariology. Vol 1. Edinburgh: Churchill Livingstone;1988. p. 718-814.

28. Brown LD, Cai TT, DasGupta A. Interval estimation for a proportion. Stat Sci 2001;16:101-133.

29. Hosmer DW, Lemeshow S. Applied logistic regression. $2^{\text {nd }}$ ed. New York: John Wiley \& Sons; 2000.

30. Hilbe JM. Logistic regression models. London: Chapman \& Hall/CRC Press; 2009.

31. Cot M, Deloron P. Paludisme associé à la grossesse: Conséquences et perspectives d'intervention. Med Trop 2003; 63:369-380.

32. Okoko BJ, Ota MO, Yamuah LK.Influence of placental malaria infection on foetal outcome in the Gambia: twenty years after Ian McGregor. J Health Popul Nutr 2002;20:4-11.

33. Brabin BJ. The risk and severity of malaria in pregnant women. Applied Field Research in Malaria Reports N. 1 Geneva: World Health Organization; 1991.
34. Nosten F, Terkuile FO, Maelankirri L, Decludt B, White NJ. Malaria during pregnancy in an area of unstable endemicity. Trans R Soc Trop Med Hyg 1991;85:424-429.

35. Andrews L, Andersen RF, Webster D, Dunachie S, Walther RM, Bejon P, et al. Quantitative real-time polymerase chain reaction for malaria diagnosis and its use in malaria vaccine clinical trials. Am J Trop Med Hyg 2005; 73:191-198.

36. Malhotra I, Dent A, Mungai P, Muchiri E, King CL. Real time quantitative PCR for determining the burden of Plasmodium falciparum parasites during pregnancy and infancy. J Clin Microbiol 2005; 43:3630-3635.

37. Rantala AM, Taylor SM, Trottman PA, Luntamo M, Mbewe B, Maleta K, et al. Comparison of real-time PCR and microscopy for malaria parasite detection in Malawian pregnant women. Department of International Health, University of Tampere Medical School, Tampere, Finland Malar J 2010; 9:269.

38. World Health Organization Expert Committee on Malaria. World Health Organ Tech Rep Ser 2000; 892: i74.

39. Figuereido P, Benchimol C, Lopes D, Bernardino L, Rosário VE, Varandas L, et al. Prevalence of pfmdr1, pfcrt, pfdhfr and pfdhps mutations associated with drug resistance in Luanda, Angola. Malar J 2008;7:236.

40. Guthmann JP, Ampuero J, Fortes F, van Overmeir C, Gaboulaud V, Tobback S, et al. Antimalarial efficacy of chloroquine, amodiaquine, sulfadoxinepyrimethamineand the combinations of amodiaquine + artesunate and sulfadoxine-pyrimethamine + artesunate inHuambo and Bié provinces, CentralAngola. Trans R Soc Trop Med Hyg 2005;99:485-492.

41. Wilson NO, Ceesay FK, Obed SA, Adjei AA, Gyasi RK, Rodney P, et al. Intermittent preventive treatment with sulfadoxine-pyrimethamine against malaria and anemia in pregnant women. Am J Trop Med Hyg 2011;85:12-21. 